\title{
Un futuro para la economía colaborativa y los nuevos modelos de negocio en las plataformas digitales*
}

\author{
A future for the sharing economy and the new \\ business models on digital platforms
}

\author{
Miguel Ferrer \\ Abogado. Asesor en políticas públicas \\ Antonio Maudes \\ Técnico Comercial y Economista del Estado
}

\section{Resumen}

$L a$ «economía colaborativa», economía de plataformas o economía P2P, constituye un modelo de negocio relativamente reciente basado en una utilización más eficiente de recursos económicos infrautilizados -bienes o servicios-a través de plataformas digitales dotadas de ambientes sociales que incentivan la confianza. A través de la colaboración digital entre expertos en la materia, este artículo pretende proporcionar al lector una previsión informada de las posibles líneas de evolución de la economía colaborativa en diversos sectores económicos. Asimismo, se proponen unas conclusiones para el mejor empleo y comprensión de esta nueva familia de modelos de negocio por parte del sector privado y del sector público.

Palabras clave: economía colaborativa, plataformas, era digital, cuarto sector, modelos de negocio.

Clasificación JEL: K20, O33, O35, O38.

\begin{abstract}
The "sharing economy", platform economy or P2P economy is a recent business model based on a more efficient use of underutilized economic resources -goods or services-through digital platforms with social environments that encourage trust. Through digital collaboration between experts in the field, this article aims to provide the reader with an informed forecast of the possible lines of evolution of the "collaborative economy" in various economic sectors. Likewise, some

\footnotetext{
* Este artículo es un trabajo colaborativo, coordinado por Miguel Ferrer y Antonio Maudes, en el que han participado los siguientes expertos: Fernando Benito Sánchez (Asesor en estrategia e innovación), Javier Creus (Fundador Ideas For Change), Fernando de la Rosa (Fundador de Foxize.com, profesor vocacional), Javier García Toni (Adjunto, Secretaría de Programas y Áreas Sectoriales, Ciudadanos. Opiniones personales), Manuel Giménez Rasero (Abogado), Susana Grau Arnau (Abogada. Autoritat Catalana de la Competència. Opiniones personales), Guirado (Abogada y economista. Fundadora de LegalSharing.eu), Pedro Hinojo (Técnico Comercial y Economista del Estado. Opiniones personales), Francisco Rodríguez Bautista (Consultor, autor y fundador de startupscolaborativas.com). No todos los colaboradores están necesariamente de acuerdo con todo lo indicado en el artículo, pero sí aprecian lo suficiente el resultado final para considerar conveniente incluir su nombre como participante. Se agradecen los comentarios de la evaluadora o evaluador anónimo. Para correspondencia con los coordinadores en referencia a este artículo puede escribirse a: buzono-academia@yahoo.com.
} 
recommendations are proposed for the best use and understanding of this new family of business models by the private sector and the public sector.

Keywords: sharing economy, platforms, digital era, fourth sector, business models.

JEL classification: K20, O33, O35, O38.

\section{Introducción}

Durante las próximas décadas seguiremos participando, de forma acelerada, en una de las revoluciones tecnológicas más profundas de nuestra Historia: la revolución digital. Por su capacidad de transformar la práctica totalidad de las actividades humanas, es una innovación solo comparable con la revolución agrícola o la revolución industrial.

El tsunami tecnológico en el que nos encontramos alcanza a las infraestructuras digitales y analógicas, a los productos y servicios que recibimos, a los conceptos de consumidor y empresa y, por supuesto, a los modelos de negocio. Este es el caso de la economía de plataformas o la economía colaborativa. Estos nuevos modelos de negocio se han convertido en sinónimo de innovación y disrupción. Si bien, en ocasiones, se encuentran rodeados de polémica, trasladan la sensación de inevitabilidad y una nueva y provechosa fuente de oportunidades para mejorar el bienestar social. Hay consenso en que van a ser esenciales para la economía del futuro.

La economía colaborativa del presente, o economía $P 2 P$-de Peer to Peer o entre iguales- modifica cualitativa y cuantitativamente los tradicionales préstamos o alquileres entre familiares y amigos. La economía de plataformas configura mercados de varios lados que están cambiando la forma de compartir alojamiento, desplazarse en las ciudades y fuera de ellas o comunicarse con amigos y conocidos. Afectará a las formas por las que aprendemos, obtenemos energía, financiación o contratamos un seguro. Las plataformas cambian nuestro sistema de elegir partido político o incluso encontrar pareja. La Era Digital modifica la sociedad, la cultura, la política y, por supuesto, la economía y el derecho.

Las definiciones no son pacíficas y la rápida evolución de la economía de plataformas puede originar mutaciones y mezclas, modificando rápidamente sus fronteras. En este artículo se ha considerado que, también en el futuro, la economía colaborativa constituirá un conjunto de modelos de negocios, de producción o consumo, que permitirá a los usuarios de una plataforma digital compartir de forma social -generalmente en un ambiente de confianza- activos, bienes o servicios infrautilizados, a cambio o no de dinero ${ }^{1}$. Las repercusiones de esta innovación son inmensas también para el sector público y las administraciones. Los cambios en las personas y los mercados -la tecnología y las preferencias- obligan a adaptar las políticas públicas y la prestación de servicios sociales.

¿Hacia dónde puede ir este modelo de negocio en distintos sectores económicos? ¿Cómo afectará a los ámbitos privado y público? Este artículo busca simultáneamente ofrecer alguna respuesta a estas preguntas e innovar en el proceso de redacción del propio texto, como aportación académica, construyendo sobre el propio espíritu de la economía colaborativa.

\footnotetext{
${ }^{1}$ Maudes, Sobrino e Hinojo (2016).
} 
Los coordinadores de este artículo hemos propuesto a diversos expertos, un experimento colaborativo, sujeto a doble peer review (revisión por pares). El resultado del experimento es este artículo prospectivo y de opinión. Se pretende resumir, de forma «colaborativa» y con la visión contrastada de cada experto, cuáles son las tendencias de la economía colaborativa en diversas materias. Una «plataforma» dentro de la plataforma que representa ya el propio monográfico, gracias a la cual los autores proponen y comparten su saber, optimizando la «utilización» de su escaso tiempo. Como en la economía colaborativa, este artículo exige menor esfuerzo a cada colaborador individual y aprovecha la era digital y las economías de red. No han existido reuniones físicas ni contactos no digitales. Asimismo, se han aprovechado los principios de funcionamiento de las plataformas digitales, preparando una «infraestructura» informática en Google docs para minimizar el trabajo y que cada proveedor/usuario del artículo pudiese realizar su aportación como autor y opinar sobre otros apartados. También como en la economía colaborativa, el artículo se basa en las cadenas de confianza y en un mejor entendimiento mutuo sin necesidad, en algunos casos, de habernos conocido personalmente.

Este trabajo tiene diversos apartados, cada uno escrito por uno o varios autores, que, cuando así lo ha deseado, se le menciona como coautor del artículo. El texto ha sido sometido a los comentarios y críticas de las personas que han participado, antes de presentar el resultado colectivo al peer review que realiza el propio Cuadernos Económicos de ICE.

Nuestro objetivo es que cada sección aporte opiniones actualizadas sobre el futuro, indicando hacia dónde podría evolucionar la economía de plataformas en diversos sectores económicos, privados o públicos. En cada uno de ellos se analizan cuáles son sus oportunidades y retos. En los siguientes tres apartados, se valoran los tres sectores en los que la economía de plataformas está mostrando una penetración inicial en el mercado más rápida y disruptiva: el alojamiento, el transporte y la financiación. A continuación, se analizan tres sectores en los que las características de las plataformas digitales podrían implicar, e incluso estar ya iniciando, cambios tecnológicos revolucionarios a corto plazo: educación, sanidad y energía. Las implicaciones de las redes $P 2 P$ para la política y las administraciones públicas ${ }^{2}$, configuran los siguientes apartados. El artículo se cierra con un decálogo destinado a facilitar la adaptación de la economía y la sociedad a estos nuevos modelos de negocio y la bibliografía consolidada que han aportado los diversos autores.

\section{Alojamiento. Oportunidades y retos del sector}

El hospitium ${ }^{3}$, o pacto de hospitalidad, es una figura procedente de la época prerromana y posteriormente adoptada por los romanos bajo ese nombre. Consiste en un

\footnotetext{
${ }^{2}$ Maudes y Silos Ribas (2016).

${ }^{3}$ Rodríguez (2018).
} 
tipo de acuerdo por el que una comunidad asimilaba a miembros de otras comunidades a la suya como si perteneciesen a ella bajo condiciones de igualdad. La tésera de hospitalidad era el objeto que simbolizaba dicho pacto, mediante el cual se adquiría un compromiso hereditario de acogida y protección del extranjero.

A comienzos del siglo xx, con motivo de la boda de Alfonso XIII, los nobles europeos hicieron uso de la hospitalidad de otros nobles debido a la escasez de oferta en Madrid. A pesar de que algunos de esos nobles sí optaron por alojarse en hoteles de la capital, como fue el caso de la delegación danesa, que se alojó en el hotel Roma, otros hicieron uso de los hogares ofrecidos por sus pares.

En los años sesenta, un grupo de catedráticos de California crearon una red universitaria para el intercambio de casas de cara a alojarse y ceder sus hogares. Además de con el objetivo de reducir los costes vacacionales, la red de intercambio de casas buscaba una experiencia diferente a la hora de viajar.

Como vemos, el alojamiento en casas de desconocidos no es ni mucho menos algo novedoso, y durante toda la historia se ha hecho uso de esta opción, ya sea para suplir la falta de oferta profesional o para complementarla. La gran novedad es la escala que alcanzan las actuales plataformas de alojamiento -en sus múltiples modalidades ${ }^{4}-\mathrm{y}$ la eficiencia que representan a la hora de cuadrar oferta y demanda.

Estas plataformas digitales ${ }^{5}$, además de la escalabilidad que permiten gracias a un coste marginal de casi cero por cada usuario nuevo, reducen a su vez la asimetría de la información debido al mayor acceso a la misma, viéndose, a su vez, reducida así la incertidumbre del consumidor a la hora de contratar productos y servicios. En buena parte esto es debido a la reputación generada en las mismas y a los sistemas de validación de los perfiles que realizan las propias plataformas. En el caso del turismo, y en concreto de la actividad alojativa, esta menor asimetría informativa aumenta la necesaria confianza que requiere una actividad tan sensible como es esta. Por otra parte, los efectos de red que se producen permiten generar valor con cada nuevo usuario que forma parte de ellas. En las plataformas de alojamiento esto se traduce en una mayor oferta con cada nuevo anuncio -y mayor competencia- y mayor demanda potencial con cada nuevo usuario, aportando así mayor liquidez a las transacciones.

Entre otras, las externalidades positivas que presentan estas plataformas de alojamiento en la industria turística son las siguientes 4D's ${ }^{6}$ (Rodríguez, 2018):

- Distribución de los beneficios del turismo, pudiendo rentabilizar habitaciones libres, la casa propia mientras no se está utilizando o una segunda vivienda.

- Descentralización de la demanda, permitiendo que esta encuentre alojamiento donde no existe oferta hotelera, contribuyendo así a la menor saturación de los destinos.

${ }^{4}$ Intercambio de casas (GuesttoGuest), homesharing (Airbnb), compartir sofá de manera gratuita (Couchsurfing).

5 Tirole (2017).

${ }^{6}$ Rodríguez Marín y Muñoz García (2018). 
- Desestacionalización en algunos destinos con temporadas fuertemente marcadas debido al cierre de hoteles, permitiendo la llegada de turistas en temporada baja gracias a que los hogares están abiertos todo el año debido a los menores costes fijos.

- Desestandarización de la oferta gracias a la variedad y autenticidad frente a una oferta tradicional mucho más estandarizada, especialmente en grandes cadenas hoteleras.

A la hora de regular, se han de tener en cuenta estas externalidades positivas y buscar su aplicación a través de las políticas públicas y los planes de desarrollo. Ya se están viendo las consecuencias de algunas regulaciones limitativas que se enfocan únicamente en las externalidades negativas que supuestamente produce esta activi$\mathrm{dad}^{7}$. Tal es el caso de Palma de Mallorca, donde el Ayuntamiento de la ciudad ha prohibido la actividad en viviendas plurifamiliares y donde el comercio local ya ha visto el impacto de dicha prohibición, calculando el sector las pérdidas económicas en hasta un 30 por $100^{8}$.

Respecto a la sostenibilidad de la actividad turística, un turismo sostenible implica satisfacer las necesidades de los turistas actuales sin poner en peligro la satisfacción de las necesidades de generaciones futuras. Existen una serie de variables para medir la sostenibilidad de un destino ${ }^{9}$. Dentro de estas variables, podemos encontrar apartados donde las plataformas de alojamiento turístico son esenciales para su cumplimiento. Entre ellas, los apartados 2 (prosperidad local), 4 (equidad social), 5 (satisfacción del visitante), 6 (control local), 7 (bienestar de la comunidad) y 11 (eficiencia de los recursos). Todos estos apartados se encuentran íntimamente relacionados con las 4D's comentadas en puntos anteriores sobre las externalidades positivas de las plataformas de alojamiento turístico.

Respecto a las externalidades positivas, según Cleantech Group, 2014, en los Estados Unidos los huéspedes de plataformas como Airbnb usan un 63 por 100 menos de energía que los turistas que se hospedan en hoteles. Además, en cuanto al consumo de agua, se ahorraron el equivalente a 270 piscinas olímpicas. Asimismo, evitaron la emisión de gases de efecto invernadero por una cantidad equivalente a 33.000 coches circulando. Por último, menos de la mitad de los anfitriones pone a disposición de sus huéspedes productos de baño de un solo uso, reduciendo así los residuos generados en un 32 por 100.

A este impacto por un uso más racional de los recursos básicos, hay que unir la menor necesidad de construir nuevas unidades de alojamiento para acoger a turistas,

\footnotetext{
7 El estudio «Mito y realidad del alquiler vacacional en las Islas Baleares» ofrece una visión muy interesante sobre el impacto de las viviendas de alojamiento turístico y desmiente muchas de las externalidades que se achacan a esta modalidad de alojamiento. http://dea.uib.cat/digital Assets/430/430024_w84.pdf.

${ }^{8}$ Por ejemplo, en el artículo: «El comercio en zonas turísticas de Mallorca cae hasta un 30 por ciento en pleno verano». Recuperado en 2018 de www.mallorcadiario.com/el-comercio-en-zonas-turisticas-de-mallorca-cae-hasta-un-30-por-ciento-en-pleno-verano

9 Tal y como se propone en Mendoza y Hernández (2017).
} 
constituyendo esto un menor impacto medioambiental en los paisajes de los destinos. Este punto es especialmente interesante para destinos emergentes, cuya necesidad de nuevas construcciones para hacer crecer su oferta se ve reducida de manera drástica, teniendo este hecho impacto tanto medioambiental como económico.

$\mathrm{El}$ aumento de aplicaciones basadas en Blockchain ${ }^{10}$ supondrá un reto para las actuales plataformas, siempre y cuando estos nuevos modelos cumplan con la función para la que se creó este libro contable abierto, distribuido, transparente y descentralizado. Si a viajar de manera más económica no se le une hacerlo de manera eficiente -costes de transacción- y la seguridad durante el viaje gracias a un servicio 24/7, difícilmente estaremos frente a un modelo competidor. De cualquier manera, las externalidades negativas de la actividad subyacente, comunes estas a la actividad turística y fuente de los conflictos actuales, continuarán siendo las mismas independientemente del medio utilizado por la oferta para llegar a la demanda.

\section{Transporte}

Las plataformas tecnológicas han revolucionado el panorama de la movilidad (especialmente, la urbana), posibilitando la aparición de servicios fundamentados en la noción de compartir: el sharing (de coches, motos, bicicletas, patinetes, plazas de aparcamiento, etc.), el car pooling (vehículo compartido) y el transporte peer to peer $(P 2 P)(\text { ride-hailing })^{11}$. En cualquiera de estos servicios, el marketplace es punto de encuentro entre oferentes y demandantes y el papel de la plataforma consiste en reducir significativamente los costes de transacción y generar efectos de red en atención a su volumen de usuarios ${ }^{12}$; en resumen, tecnológicamente introducir eficiencia al máximo en el matxing entre oferta y demanda.

Pero ¿cuáles son las razones de este boom de servicios/bienes compartidos en el sector del transporte que tienen como soporte plataformas digitales $?^{13}$ En primer lugar, el desarrollo y penetración de la tecnología ha abierto unas posibilidades que hasta hace muy poco eran inimaginables. En segundo lugar, tanto la congestión del tráfico urbano como la contaminación son problemas graves, ávidos de soluciones. En tercer lugar, los recursos de movilidad se encuentran en general muy infrautilizados (el vehículo privado no se utiliza durante una parte muy importante del tiempo, cuando se utiliza es frecuente que transporte solo al conductor y eso mismo sucede con los taxis, puesto que en la mayoría de trayectos se transporta a un único pasajero). Por tanto, compartir supone una forma efectiva de aumentar la utilización de los recursos de movilidad y, en consecuencia, introduce eficiencia en el transporte: cuanto mayor sea el factor de utilización de los vehículos, menor será el número de

${ }^{10}$ Sistema de seguridad formado por bloques alojados en una base de datos compartida.

${ }_{11}$ American Public Transportation Association (2016).

${ }^{12}$ A más conductores tiene un marketplace, más posibilidades tienen los usuarios demandantes del servicio de encontrar un prestador del mismo más rápido y mejor ubicado, por ello las plataformas digitales constituyen un two sided-market que se retroalimenta positivamente.

${ }^{13}$ OCDE 2007 (2018). 
vehículos en circulación, lo que debería traducirse de manera agregada en menor congestión y contaminación ${ }^{14}$.

$\mathrm{Y}_{i}$ cómo responde nuestro marco regulatorio esta realidad? Hasta ahora las iniciativas de sharing no han encontrado muchos problemas legales -de hecho, no deja de ser un servicio de alquiler de un vehículo por un período muy corto de tiempo y con mucha flexibilidad-; el car pooling ha tenido que hacer frente a alguna reclamación judicial por competencia desleal ${ }^{15}$, pero estas no han prosperado, dado que los jueces se han mostrado favorables a la posibilidad de compartir trayecto sin que constituya un servicio de transporte sujeto a la LOTT ${ }^{16}$; y claramente, el que más controversia ha provocado ha sido el servicio de transporte peer to peer $(P 2 P)$ (ride-hailing), por no encajar adecuadamente ni en la regulación del taxi ni en la del alquiler de vehículos con conductor (VTC) y, en consecuencia, ha sido objeto de importantes acciones judiciales ${ }^{17}$. El Tribunal de Justicia de la UE consideró que esta actividad constituye un servicio de transporte y la legislación estatal exige contar con un título habilitador para ejercer la actividad (de taxi o de VTC), lo que ha provocado que no existan plataformas de servicios de transporte de viajeros peer to peer en España.

En otros términos, la normativa actual de transporte de viajeros en vehículos de hasta nueve plazas está cargada de ineficiencias que persiguen un «supuesto» y artificial equilibrio entre el sector del taxi (configurado como servicio de interés general) y el del VTC y que no contempla en modo alguno la realidad de la economía digital en el mercado de transporte de viajeros.

Más allá de su configuración legal, las plataformas digitales en el mundo del transporte introducen eficiencias en el uso de los recursos, facilitan la entrada de nuevos operadores en el mercado y generan un incremento de competencia con los beneficios tradicionalmente asociados a esta ${ }^{18}$ : variedad de oferta, mejores precios y/o condiciones comerciales, innovación...

Por ello, la actuación de los poderes públicos debería encaminarse a propiciar un entorno de mercado que posibilite el desarrollo de la actividad de las plataformas de transporte reconociendo derechos y obligaciones a sus operadores; de manera que las limitaciones legales para operar (entendidas como barreras a la entrada o requisitos de ejercicio) respeten el principio de necesidad, proporcionalidad, no discriminación y de mínima distorsión, de acuerdo con las exigencias de la política better regulation ${ }^{19}$.

Sin embargo, los operadores tradicionales sienten presiones competitivas provocadas por la irrupción de las plataformas y reaccionan de manera organizada y eficaz a fin de mantener las ineficiencias de la legislación actual, puesto que tienen

${ }^{14}$ Comisión Europea (2016).

15 Sentencia del Juzgado Mercantil n. 2 de Madrid, n. ${ }^{\circ}$ 30/2107, de 2 de febrero de 2017.

16 Ley 16/1987, de 30 de julio, de Ordenación de los Transportes Terrestres.

17 Sentencia del Tribunal de Justicia de la Unión Europea de 20 de diciembre de 2017 (asunto Elite Taxi/ Uber).

18 Vid.ACCO (2012, 2014, 2016, 2018a, 2018b) y CNMC (2016a, 2016b, 2017a).

19 AFI (2017). 
dificultad para adaptarse a las nuevas exigencias del mercado. Recientes actuaciones regulatorias no dejan lugar a duda de cuál es la línea en la que trabaja el legislador. Vamos a exponer dos ejemplos:

- Limitación de la capacidad operativa de los VTC. Esta intención es clara si tenemos en cuenta: $a$ ) la elevación a rango legal de la ratio 1 VTC / 30 TAXIS mediante el Real Decreto Ley $3 / 2018^{20}$-se trata de una regulación preventiva, dictada por si el Tribunal Supremo hubiera anulado la previsión infra legal de la referida ratio (cosa que no sucedió $\left.{ }^{21}\right)-; b$ ) el intento de exigencia de un segundo título, de carácter local, habilitante del ejercicio de la actividad de VTC, capitaneada por el Área Metropolitana de Barcelona (AMB) ${ }^{22} ; c$ ) la expulsión (diferida o no) de los VTC en el ámbito urbano, a través de la aprobación del Real Decreto Ley $13 / 2018^{23}$ y (iv) la reciente apertura de un nuevo proceso regulatorio, también por parte de la AMB, para regular la actividad de los VTC's ${ }^{24}$, ahora ya sí al amparo de una norma, a saber, el Real Decreto Ley 13/2018.

Así, a pesar que las plataformas digitales, que gestionan flotas de vehículos que cuentan con autorización VTC, introducen presiones competitivas claras en el sector del taxi que benefician a los usuarios, puesto que recordemos: el precio es libre, la calidad es notable -o así lo aprecian los usuarios- y además actúan en régimen de pre-contratación, es decir, no circulan vehículos vacíos a la caza del cliente, la opción del legislador está claramente encaminada a hacer desaparecer, más o menos rápido según el caso, esta modalidad de transporte a nivel urbano.

- Restricciones a la actividad de sharing. El Ayuntamiento de Barcelona: $a$ ) modificó, en febrero de 2017, la Ordenanza de Circulación de Peatones y Vehí$\operatorname{culos}^{25}$ prohibiendo la actividad de sharing de patinetes eléctricos ${ }^{26}$, y $b$ ) ha presentado el Proyecto de regulación de la actividad de sharing de bicicletas y motocicletas que limita el número de vehículos destinados a esta actividad ${ }^{27}$, además de gravar con una tasa a cada una de las bicis o motos compartidas, por la ocupación de la vía pública. ¿Será que el resto de vehículos (pensemos en los privados o los de alquiler desde un establecimiento) no ocupa la vía pública? ${ }^{28}$.

\footnotetext{
${ }^{20}$ Real Decreto-ley 3/2018, de 20 de abril, por el que se modifica la LOTT, en materia de VTC.

${ }^{21}$ Sentencia Tribunal Supremo n. ${ }^{\circ}$ 921/2018, de 4 de junio de 2018 (Roj: STS 1913/2018 - ECLI: ES:TS:2018:1913).

${ }^{22}$ Nos referimos a intento, en tanto que el Tribunal Superior de Justicia de Catalunya ha concedido medida cautelar de suspensión del Reglamento de la AMB por considerar que concurre fumus boni iuris en la extralimitación competencial de la norma.

${ }^{23}$ Real Decreto-ley 13/2018, de 28 de septiembre, por el que se modifica la LOTT.

${ }^{24} \mathrm{http} / /$ www.amb.cat/es/web/amb/actualitat/sala-de-premsa/notes-de-premsa/detall/-/notapremsa/l-amb-obre-un-proces-participatiu-per-a-l-aprovacio-d-una-norma-reglamentaria/7308457/11696.

${ }^{25} \mathrm{https} / / /$ bop.diba.cat/scripts/ftpisa.aspx?fnew?bop2017\&02/022017003086.pdf\&1

${ }^{26} \mathrm{http}$ ://ajuntament.barcelona.cat/bicicleta/ca/regulacio-de-vehicles-de-mobilitat-personal-i-cicles-de-mes-de-dues-rodes

${ }_{27} \mathrm{https}: / /$ ajuntament.barcelona.cat/premsa/2018/11/13/proposta-de-regulacio-dels-serveis-de-bici-i-moto-de-vehicle-compartit/

${ }_{28} \mathrm{https} / / /$ ajuntament.barcelona.cat/premsa/2018/11/23/saprova-provisionalment-la-taxa-docupacio-de-lespai-public-per-regular-el-serveis-de-bici-i-moto-compartits/
} 
Por tanto, aunque se trata de servicios que fomentan la eficiencia por vehículo (más rotación por vehículo), no generan contaminación (son vehículos eléctricos o pulmonares), contribuyen decididamente al transporte de última milla favoreciendo así el uso del transporte público y numéricamente constituyen una porción minúscula del parque total de estas tipologías de vehículos en la ciudad, la opción del legislador es prohibirlos -caso de los patinetes eléctricos- o establecer un número máximo de vehículos dedicados a esta actividad -caso de las motocicletas o bicicletas.

Como vemos, la reciente realidad regulatoria en el mundo del transporte urbano de viajeros no deja mucho espacio al optimismo; sin embargo, en atención al interés general, no hay opción a paralizar la innovación en la movilidad. Por tanto, es precisa una transición de modelo regulatorio que permita superar las ineficiencias del actual marco normativo y aprovechar los beneficios inherentes a las innovaciones de base tecnológica. Es decir, si la digitalización es potente y disruptiva, ¿por qué la vamos a dejar de lado en el sector del transporte? No es de recibo. Existe amplio recorrido para la mejora en este sector -precios, calidades, tiempos de espera, servicios novedosos, etc.-, pero, además, introducir eficiencia en el sector transporte impacta directamente en aspectos que repercuten en la calidad de vida de todos: congestión, medio ambiente, uso del espacio público, etc. ¿Por qué hay que esperar para mejorar el bienestar social? ¿No podemos contrastar hipótesis ya con pruebas piloto?

Un nuevo entorno de mercado más flexible y digital, que garantice las condiciones de competencia, la seguridad del servicio y la protección del usuario, debería asentarse sobre estos pilares:

- Compartir vehículos y servicios de transporte, usando eficientemente los recursos disponibles. Se trata de hacer entrar al mercado bienes de uso privativo, de manera que se transite del paradigma de la propiedad hacia el del uso, con el objetivo de reducir los vehículos en circulación y así mejorar en términos de congestión, polución, uso del espacio público, etc. Sin olvidar, los beneficios directos para los usuarios.

- Complementar el transporte público mediante movilidad compartida. Va a ser necesario unir esfuerzos con la iniciativa privada, a fin de poder poner a disposición del ciudadano la mejor oferta posible de servicios de transporte.

- Promover al máximo la intermodalidad en el servicio de transporte, poniendo en valor la agregación -de información, medios de pago y servicios- de todas modalidades de transporte, ya sean públicas o privadas, a fin de ofrecer la respuesta más idónea para cada demanda de servicio (mobility as a service).

- Abastecer de datos a los poderes públicos referentes a: movilidad, incidentes de seguridad, orden público, etc., para facilitar un mejor diseño e implementación de políticas y decisiones públicas, así como su evaluación ex post. Fomentar los datos públicos abiertos y API (interfaz de programación de aplicaciones), para promover soluciones integradas de movilidad, así como apoyar el desarrollo y adopción de estándares de información de movilidad. 
- Regular de manera innovadora, de manera que cuando sea necesario restringir una actividad, por la existencia de fallos de mercado, para garantizar la accesibilidad y/o la equidad o por otros motivos de interés general -no confundir con interés de un colectivo-, se establezcan limitaciones temporales, dinámicas, por zonas, etc. Esto es: restricciones proporcionadas para evitar sacrificios injustificados a la competencia.

Las plataformas pueden contribuir decididamente a la transformación de la movilidad creando un ecosistema de vehículos limpios y servicios de movilidad compartida $^{29}$ que complementen el transporte público. La afectación al transporte público (servicios urbanos de autobús, concesiones de transporte regular interurbano, etc.) constituye una oportunidad magnífica de redefinir servicios, de acuerdo con las nuevas necesidades, y prestar nuevos servicios más eficientes (bus on demand). Así, las diferentes formas de transporte público han de aprender, beneficiarse e interactuar con los servicios de transporte de base tecnológica.

En resumen, los decisores públicos deben evaluar y aprovechar las posibilidades que ofrecen las plataformas digitales como elemento dinamizador de la economía, la eficiencia, el servicio al ciudadano, el empleo y la modernización del país. Y es que, más allá de la irrupción de las plataformas tecnológicas, el sector del transporte experimentará en los próximos tiempos una profunda transformación provocada por: el cambio del modelo energético y la automatización e implantación progresiva del coche eléctrico autónomo.

Debe reconocerse la dificultad de abordar esta transformación, dado que se mezclan, por una parte, intereses contrapuestos que hay que tratar con habilidad, de forma equilibrada y a un ritmo idóneo - pero huyendo de políticas proteccionistas- y de otra, los retos de la regulación de esta nueva forma de organización industrial: la digitalización.

\section{Finanzas}

La aplicación de las nuevas tecnologías de la información y las comunicaciones (TICs) al ámbito de finanzas (Fintech) y seguros (Insurtech) supone una auténtica disrupción por dos vías (CNMC, 2018):

- Por un lado, una transformación en la forma de negocio y de organización de transacciones, fundamentalmente a través de la irrupción del modelo de plataforma. Esto supone una «desintermediación» de la tradicionalmente muy inter-

${ }^{29}$ Para maximizar el potencial transformador de las plataformas va a ser necesaria la adopción de políticas públicas de diversa índole que persigan, por ejemplo: $a$ ) potenciar los vehículos limpios y la creación de puntos de recarga; $b$ ) establecer precios de congestión; $c$ ) implantar precios dinámicos para los servicios de transporte público (precios más reducidos en episodios de contaminación); d) evitar desplazamientos innecesarios (fomentando el teletrabajo y flexibilidad horaria), etc. 
mediada actividad financiera, que en el caso más extremo podría ser la implantación del modelo $P 2 P$ (peer-to-peer o transacciones entre iguales).

- Por otro lado, aunque relacionado con lo anterior, la involucración del consumidor (Nicoletti, 2017) y una mayor orientación a la satisfacción de sus necesidades (customer centricity). Esto supone una «disgregación» (unbundling) del sector financiero, pudiéndose optar por diversos operadores «de nicho» en función de cuál ofrezca el servicio más competitivo en cada caso en lugar del tradicional modelo de ventanilla única (one-stop shop).

Esta disrupción en el sector financiero se ha iniciado de manera más tardía y más lenta que en otros ámbitos (como alojamiento o transporte), por diversas razones:

- En primer lugar, el sector financiero es muy sensible para el consumidor, que puede mostrar aversión al riesgo ante cambios de proveedor (WEF, 2017) hacia nuevos operadores o hacia oferentes atomizados o no puramente profesionales. La señal de marca de grandes e históricos operadores ya instalados puede ser una poderosa herramienta de fidelización.

- En segundo lugar, por esta sensibilidad del sector financiero y la incidencia de crisis con enormes costes fiscales, económicos y sociales, la regulación tiende a ser sumamente restrictiva, en cuanto a requisitos de entrada y a barreras de ejercicio. Sobre todo por las reservas de actividad, que en ocasiones abocan al modelo de ventanilla única (one-stop shop) e impiden a competidores de nicho aprovechar eficiencias y economías de alcance en ciertos segmentos.

- En tercer lugar, los operadores tradicionales en el sector financiero están mejor equipados para adaptarse a esta disrupción en comparación con operadores tradicionales de otros sectores, por causas adicionales a las dos anteriores. Aunque hereden infraestructuras costosas, se benefician de economías de red en ciertos ámbitos (WEF, 2017), especialmente mayoristas (como sistemas de compensación o plataformas de negociación). Además, los operadores instalados ya estaban acostumbrados, o al menos sensibilizados, al manejo de datos, una de las grandes ventajas comparativas de nuevos entrantes.

- En cuarto lugar, precisamente por la importancia vital del manejo de datos en el sector, la competencia a los operadores tradicionales emana no tanto de «prosumidores» sino de empresas especializadas en este ámbito (Zetzsche et al., 2017), que aplican su expertise a finanzas al igual que en otros sectores (TechFin). Esto apunta a la entrada generalizada de las grandes empresas tecnológicas (Bigtech), que, por los antedichos factores tanto regulatorios como económicos, pueden optar por la prestación directa y no tanto por la labor pura de plataforma de intermediación (matchmaker) entre «prosumidores». El ámbito donde esto es más visible a corto plazo es el de los pagos (Deutsche Bundesbank, 2016), aunque este marco es fácilmente generalizable a otros servicios como la financiación (crowdfunding) o el asesoramiento. 
No obstante, aunque haya factores que ralenticen la disgregación y la desintermediación del sector financiero, los modelos colaborativos y de plataforma tienen un enorme potencial (en algunos casos, ya materializado), especialmente en el segmento minorista:

- El ejemplo más claro sería el de los microseguros (con seguros entre particulares y a demanda) y el de las microfinanzas (con financiación entre particulares o hacia proyectos concretos a través de plataformas de crowdfunding).

- Otros servicios de mayor valor añadido son los de asesoramiento financiero y gestión de carteras. En este caso, se pueden utilizar herramientas propias de la economía colaborativa y las redes sociales, como los mecanismos de reputación para permitir a proveedores atomizados generar esa señal de marca que atraiga a consumidores y genere externalidades de red (siendo el ejemplo más paradigmático el del social trading).

- Las tecnologías de registro distribuido (DLTs, distributed ledger technologies) pueden aplicarse de manera horizontal al sector financiero, como en las áreas de pagos y financiación, contribuyendo a la desintermediación y la disgregación.

En definitiva, los nuevos modelos de economía colaborativa y plataformas digitales también están transformando el sector financiero. Y ello es clave para que se desarrollen otros ámbitos sectoriales cubiertos en este artículo. Gracias a la desintermediación y la disgregación en el sector financiero, los nuevos negocios pueden captar financiación por vías alternativas al tradicional canal bancario o bursátil (costoso y no muy abierto a empresas pequeñas, nacientes o innovadoras), facilitando el nacimiento y desarrollo de innovaciones en todos los sectores.

\section{Educación en la era de las plataformas}

La «economía de las plataformas» dejará, sin ningún tipo de duda, su huella en la sociedad y de la misma manera lo hará sobre la educación. Lo que no queda claro es en qué aspecto. ¿Será un cambio positivo o, por lo contrario, nos encontraremos con monopolios mundiales que dominen la educación? Puede suceder que las personas compartan más y mejor su conocimiento o también puede ocurrir que la profesión docente se precarice del mismo modo que ha ocurrido con los conductores de Uber. En las próximas líneas pretendo dar un punto de vista muy personal sobre el impacto de la economía de las plataformas en la educación y con algunas ideas que espero que ayuden a la reflexión en un tema tan importante para la sociedad.

Hablar del mercado de la educación -en toda su amplitud- requiere de un esfuerzo de precisión para evitar errores conceptuales. Para contextualizar el cambio que se avecina, creo que es necesario entender cuatro características importantes de este sector: 
- Multiciclos: El mercado de la educación es uno los sectores más importantes de la sociedad al que estamos vinculado en menor o mayor medida a lo largo de toda nuestra vida. Cada contacto con el sector pertenece a un ciclo con características singulares. Por ejemplo, la educación primaria -que está regulada- no tiene nada que ver con la formación profesional. Por tanto, toca precisar a qué ámbito nos referimos cuando hablamos de los cambios que afectan o afectarán a la educación.

- Un mercado atomizado: En el sector de la educación participan muchísimos actores y muy variados. Para que haya un cambio significativo sería necesario agrupar los intereses de todos estos actores y, sobre todo, romper los frenos que imponen. Esta atomización implica que el cambio no sea rápido.

- Formación $v s$. aprendizaje. La industria de la formación nunca antes ha generado tanto volumen de negocio como a día de hoy, pero también es cierto que nunca antes ha habido una crisis tan grande en la forma de aprender. Por desgracia, cuando un negocio va bien tiene pocos incentivos para cambiar.

- Lento retorno de inversión. Cualquier proyecto que quiera demostrar una mejora en el aprendizaje de las personas requiere de tiempo, justamente lo que no tienen los fondos de inversión. Los ciclos en educación son largos y lamentablemente desincentivan la inversión en el sector. Esto provoca que los cambios también sean más lentos.

Viendo la complejidad de este mercado se antoja poco probable que pueda aparecer una meta-plataforma educativa que transforme el sector. La mayoría de las iniciativas que van surgiendo en este contexto y ámbito están enfocadas a solucionar un problema concreto dentro de uno de los mencionados ciclos. Además, como hemos visto, se trata de un sector relativamente lento y con pocos incentivos para lograr cambios significativos a corto plazo. Parece - a priori- que habrá poca disrupción en el sector.

Pero quizá este enfoque no es el que nos sirva para entender por dónde pueden aparecer realmente los cambios. Quizá deberíamos observar el mercado de la educación desde otro ángulo: desde la revolución digital y su impacto en él.

La economía de las plataformas a mi entender no es más que una fase extra dentro la revolución digital en la que estamos inmersos. Una revolución que ya está transformando la base en la que se moverá el mercado de la educación. Estos son algunos de los impactos que ya se pueden observar:

- Formación continua: A mayor innovación tecnológica, más necesidad tendremos de estar al día para poder mantenernos en el mercado laboral. En consecuencia, irán aumentando paulatinamente los contactos con el sector.

- Experiencias educativas personalizadas: Los hábitos de consumo de la sociedad han cambiado -y mucho- en los últimos años. Hoy por hoy, las personas buscan la personalización a la hora de consumir contenidos. Y estamos ante un fenómeno que no solo afecta a los contenidos de entretenimiento, también se 
ha extrapolado a otros terrenos como el de la educación. Sin personalización, el interés de los alumnos irá bajando cada vez más. Pero además, desde mi punto de vista, lo peor es que puede provocar un sentimiento de «fracaso» en ellos por ser incapaces de hacer ese esfuerzo extra por aprender.

- El problema de la atención: Frente a la abundancia de contenidos, el recurso cada vez más escaso será la atención y el foco. Existen ya en la actualidad innumerables casos de déficit de atención. Y evidentemente, la solución no pasa por medicar a la sociedad.

- Nuevas formas de aprender: Si cualquier información, a día de hoy, la podemos encontrar a través de los buscadores, entonces, ¿qué deberíamos o no aprender? El acceso a la información nos plantea un reto enorme en educación, ya que tenemos que crear nuevas metodologías de aprendizaje.

- La certificación perderá peso: El valor de un proyecto educativo reside hasta ahora en tres variables: acceso a conocimiento relevante, acceso a experiencias educativas transformadoras y en el valor de su certificación. Las dos primeras variables se han estandarizado; la tercera, sin embargo, creemos que será la que más presión soportará en un futuro próximo. ¿Por qué digo esto? Porque el valor de la certificación solo se podrá mantener estable hasta que el mercado laboral exija un cambio en la forma de contratar candidatos, y esto irá mucho más allá que el currículum académico.

- Modas digitales: En educación, como en otros muchos ámbitos, se recogen las novedades que proporciona la tecnología con la esperanza que sean la solución a nuestros problemas. Pero, en general, estas modas tienen escaso impacto a corto plazo. Un ejemplo, los famosos MOOC (Massive Online Open Courses), que llegaron con fuerza como alternativa a la enseñanza profesional, pero que no han conseguido altas tasas de finalización entre los alumnos.

Vemos que el reto en educación es mayúsculo, pero hay una pregunta clave que nos falta por responder: ¿hacia dónde vamos?

La palabra formación implica dar una «forma». Pero, ¿qué forma debemos dar a los alumnos? ¿Les ayudamos a formarse para tener un empleo concreto que existe a día de hoy, pero que no sabemos si existirá mañana? La crisis actual del sector educativo radica precisamente en este punto: No sabemos qué futuro nos espera, y por tanto no sabemos cómo hay que preparar a los alumnos. Frente a este dilema, nos encontramos con dos visiones contrapuestas sobre la educación del futuro:

Visión 1.-La educación sirve para mejorar la empleabilidad y encontrar un mejor trabajo. Una mejor educación debería garantizar un mejor empleo.

Visión 2.-La educación debería ayudar a las personas a ser más libres para poder abordar los retos del futuro que viene con la mejor preparación ética posible y con mayor conciencia social. En una sociedad en la que no habrá empleo para todos a causa de la robotización, necesitaremos aprender a pensar de forma diferente, más allá del interés individual. 
En la actualidad, el sector educativo no tiene clara la visión a seguir frente a un mundo tan complejo como el que viene en los próximos años. Creo que se encuentra en plena transformación, pero sin una dirección clara de hacia dónde debería ir. La velocidad -sumamente lenta- de los cambios en este sector provoca una profunda preocupación, sobre todo en el ámbito empresarial que se pregunta dónde conseguirá el talento tan necesario para su crecimiento. Por otro lado, a nivel individual, la gente se plantea cómo estudiar y trabajar para no perder su trabajo. Y por último, aunque no menos importante, debemos preguntarnos qué tipo de sociedad estamos creando.

Respecto al impacto de las plataformas digitales en el sector de la educación, como ya hemos visto, la irrupción de la economía de las plataformas no ha provocado un cambio significativo. Los problemas con los que nos encontramos en este mercado a día de hoy son tan estructurales que la lógica de compartir recursos infrautilizados que plantean las plataformas digitales no es capaz todavía de abordar las principales cuestiones y problemáticas de fondo del sector.

No obstante, el que no exista una gran plataforma educativa, no significa que el mercado de la educación no pueda verse afectado por la economía de las plataformas. Existe un efecto colateral: la precarización del mercado laboral, aprovechado por algunas plataformas digitales, romperá en algún momento la relación estudio/ trabajo. Hay muchas personas preparadas, con estudios, que no encuentran el trabajo para el que han sido formados. En muchas ocasiones, el mercado laboral no les deja otra alternativa que aceptar trabajos por debajo de su nivel de estudios. Y es aquí donde puede surgir, si la situación no mejora, un efecto significativo: La ruptura en la confianza del sector educativo como mecanismo de acceso al trabajo. Un efecto que podría convertirse en la gota que colme el vaso, y que obligue a acelerar la transformación de la educación que a día de hoy no llega.

\section{Sanidad: los ciudadanos y sus datos, las claves de la transformación}

Nuestro sistema de sanidad está bajo una enorme presión: la población envejece, las enfermedades mentales crecen y el resto se cronifican. Una demografía decreciente, el paro estructural y la precariedad del trabajo no permiten anticipar la disponibilidad de nuevos fondos públicos para atención sanitaria.

Mientras, los avances tecnológicos y la innovación social abren un nuevo horizonte de lo posible. En la reducción de costes: aplicaciones, pulseras, collares, tablets, implantes que generan datos que pueden ser monitorizados y quizá accionados a distancia. Análisis genéticos de bajo coste, análisis específicos de usar y tirar. Algoritmos que leen radiografías o anticipan ataques de epilepsia mejor que cualquier médico ${ }^{30}$. Información disponible en todos los medios, foros de pacientes, tele-seguros médicos, robots de compañía. En sistemas de apoyo a los ciudadanos: vecinos y comercios se organizan para cuidar de sus mayores. Equipos de cuidadores

${ }^{30}$ https://www.elperiodico.com/es/sanidad/20181025/epilepsia-audifono-aviso-movil-7110230 
que se autoorganizan para atender un barrio. Establecimientos clínicos que se alquilan equipos mutuamente. Redes de intercambio de artículos ortopédicos.

Vamos a enfocarnos en la salud y no estrictamente en la sanidad. El estado de salud de una persona depende un 20 por 100 de lo clínico y un 10 por de lo genético; un 40 por 100 de los hábitos de vida -lo que más- y otro 30 por 100 del nivel socio económico ${ }^{31}$. Las enfermedades de nuestro tiempo tienen tanto que ver al menos con los virus y las bacterias como con el aire que respiramos, el lugar en el que habitamos, lo que comemos y caminamos o si lo hacemos solos o en compañía.

Nuestro reto colectivo es combinar el potencial de la innovación científica y tecnológica con las aspiraciones y necesidades de una ciudadanía con capacidades aumentadas, capaces de generar datos y evidencias, de producir alojamiento, transporte, financiación, conocimiento, comunidad. El objetivo es diseñar sistemas de lógica colaborativa que nos permitan hacer más con menos para proveer de condiciones y atenciones de salud al conjunto de la población. Contamos con la precisión y anticipación de la inteligencia artificial; la confianza mutua y en lo común de la inteligencia social; y el gobierno de los datos de nuestra inteligencia colectiva. Un nuevo sistema operativo social para la salud.

Con datos clínicos desde luego, pero con muchos otros datos de la actividad y la circunstancia personal que antes eran difíciles de obtener fuera de un ambiente artificial, y que ahora generamos de forma muchas veces involuntaria a través de sensores en nuestro cuerpo, pegados a nuestra piel o en los objetos y el ambiente que nos rodean. Pasos y actividad física, sueño y pulsaciones. Miles de personas viven ya con un chip implantado que les permite abrir puertas y acelerar gestiones de la vida cotidiana ${ }^{32}$, cyborgs $\sin$ glamour. Gotas de datos en un océano de datos en el que los edificios, las instalaciones, la maquinaria, los vehículos, los profesionales de la medicina, los familiares y los vecinos y comercios cercanos también participan.

Son los flujos de datos los que empujan la frontera de lo posible. Los sistemas de inteligencia artificial necesitan datos para visibilizar lo infrautilizado; para optimizar ocupaciones, rutas y turnos; para leer e interpretar pruebas e informes clínicos, anticipar crisis episódicas y dosificar medicamentos en tiempo real; para emparejar necesidades, encontrar personas cercanas o afines, o para educar a los robots. Pero la salud no depende solo de los datos, depende en buena medida también de la relación con uno mismo y con los demás: la depresión, el suicidio, la soledad, las trampas de la sociedad del cansancio ${ }^{33}$.

La atención al individuo aislado de su comunidad -los derechos individuales del estado del bienestar- no ha conseguido tras cincuenta años de su implantación en Suecia evitar una alarmante epidemia de soledad ${ }^{34}$. La salud necesita también de personas integradas -activas en la medida de sus posibilidades- en una red humana

${ }^{31}$ Sevilla y Riesgo (2018).

${ }^{32}$ www.npr.org/2018/10/22/658808705/thousands-of-swedes-are-inserting-microchips-under-their-skin

${ }^{33}$ Byung-Chul (2014).

${ }^{34}$ https://elpais.com/elpais/2018/02/19/opinion/1519045037_011714.html 
de afecto y apoyo mutuo. La familia extensa con capacidad y voluntad de acoger y apoyar a los miembros de más de dos generaciones es una excepción entre las familias pequeñas, des o reestructuradas, dispersas geográficamente de nuestro tiempo. Por otra parte, la familia se acepta, no se escoge. Acoge en su techo, pero no necesariamente permite el pleno desarrollo de cada uno de sus miembros.

Necesitamos complementar los lazos familiares por lazos civiles, una familia de adopción, y aquí es donde la lógica colaborativa cobrará protagonismo como generadora de encuentros y relaciones. Hacer juntos, intercambiar capacidades, ensayar nuevas fórmulas de cohabitar las viviendas y para la organización de cuidados vecinales, para la pacificación medioambiental -aire, ruido, olores- de las ciudades, para la conquista y habilitación del espacio para el uso público, la dinamización cultural y social del territorio.

La presión de los costes de los sistemas de salud invita a reasignar los roles que ejercen cada uno de sus participantes en función de sus capacidades propias y disponibles en los sistemas de apoyo a los que tenga acceso. Ciudadanos con capacidad para la realización de pruebas clínicas y generación de información sobre su estado de salud: viviendas habilitadas sanitariamente funcionan como satélites de hospitales cercanos; redes mixtas de ciudadanos y cuidadores atienden a colectivos en los barrios; la atención primaria se desplaza cada vez más al teléfono y al hogar, algunos diagnósticos especializados se pueden ofrecer en consulta virtual; las máquinas de curar quedan en el hospital.

Es la energía de los datos -generados por los propios ciudadanos- la que determina la velocidad a la que la transformación del sistema será posible. Serán los derechos sobre los datos los que determinen hasta qué punto los ciudadanos podrán afectar a los fines y valores de la transformación. Angela Merkel afirmó en la Cumbre de Davos 2018 que: «La respuesta a la pregunta ¿De quién son los datos? determinará si la democracia, un modelo social participativo y el progreso económico son compatibles». Nuevas fórmulas organizativas como cooperativas de datos en las que los ciudadanos deciden en qué condiciones comparten sus datos para la investigación en salud ${ }^{35}$ pueden, aplicando la lógica colaborativa, encontrar soluciones viables a la ecuación que Merkel nos plantea.

\section{Energía}

Antes de entrar a valorar cuáles pueden ser las perspectivas político-regulatorias en el sector energético desde el punto de vista de la economía de plataformas, conviene hacer una breve introducción sobre las peculiaridades de este $\operatorname{sector}^{36}$, y más concretamente, del sector eléctrico, que es en el parece serán viables realmente las transacciones $P 2 P$ entre consumidores.

\footnotetext{
35 www.saluscooop.org

36 Vives (2006) y Guirado (2006).
} 
El sector eléctrico se compone de cuatro actividades: la actividad de generación [con tecnologías diversas como fuentes renovables (fotovoltaica, eólica, etc.), hidroeléctrica o térmica (con combustible nuclear, de carbón o fuel)]; la actividad de transporte de la electricidad producida en redes de alta tensión; la actividad de distribución (transmisión de energía eléctrica desde las redes de transporte / distribución o desde la generación conectada a la propia red de distribución, hasta los puntos de consumo u otras redes de distribución, con el fin último de suministrarla a los consumidores) y la actividad de comercialización ${ }^{37}$. Las fases de transporte y distribución son un monopolio natural, sujeto a regulación, mientras que las fases de generación y comercialización están abiertas a la competencia.

Como principal peculiaridad del sector eléctrico, destaca el que, con carácter general, la electricidad no es almacenable (salvo en las presas hidráulicas y, ahora también, vía baterías) y, por tanto, debe generarse mayormente en el momento en el que se consume. Ello trae consigo la necesidad de la figura del «operador del sistema», que supervisa que se case la oferta y demanda de energía eléctrica, minuto a minuto, al precio de mercado o «precio marginal», que es el precio que fija la última central en entrar al «pool eléctrico» para atender a la demanda que se ha solicitado para ese día. Ese precio marginal, junto con el resultante de la entrada en funcionamiento de determinadas centrales, que se ponen en marcha, por seguridad de suministro, debido a la existencia de «restricciones técnicas», para evitar que haya cortes de electricidad, constituyen el precio del mercado mayorista.

Ello coincide con que se trata de un sector que, desde el lado de la oferta, cuenta con enormes costes, debido a: $a$ ) el encarecimiento de las fuentes primarias de energía (combustibles fósiles); $b$ ) la presencia, cada vez mayor, de generación renovable solar y eólica, cuya producción depende de la disponibilidad instantánea e impredecible de las fuentes renovables primarias, sol y viento; $c$ ) la instalación de generación distribuida (renovable y no renovable), con características de estar próxima al consumo y de baja controlabilidad; y d) como consecuencia de los dos últimos, el aumento de la proporción de generación «tradicional» que actúa como backup de generación, sufriendo estos activos una gran infrautilización, lo que se traduce en un coste adicional para el sistema. A su vez, se trata de un sistema, falto de transparencia, tanto en la fijación de los costes marginales que llevan a la determinación final del precio de la energía, como en cuestiones tan sencillas, como la simple lectura de la factura de la luz $z^{38}$.

En este contexto, tanto demanda como oferta son prácticamente inelásticas a corto plazo. La demanda es inelástica porque los consumidores, especialmente los domésticos, suelen acogerse a una tarifa regulada, ahora denominada PVPC (Precio Voluntario al Pequeño Consumidor), y porque, además, la renta apenas influye en la factura eléctrica, lo que permite definir a la electricidad como un bien de primera necesidad, con una elasticidad próxima a cero; mientras que las variables que sí influ-

\footnotetext{
37 Anales de Mecánica y Electricidad (2013).

38 CNMC (2017b).
} 
yen en la factura eléctrica de un hogar, son el número de miembros y de la vivienda $\left(\mathrm{m}^{2}\right)$. De igual modo, la oferta es relativamente inelástica, dado que la electricidad no puede mayormente almacenarse y existen restricciones de capacidad de oferta en el corto plazo.

A pesar de esa inelasticidad de la demanda, se trata de un sector en el que los consumidores son especialmente sensibles al precio y a sus variaciones.

A la luz de todo lo anterior, podemos aventurar que la evolución del sector se presenta vía mayor involucración del consumidor, para la satisfacción de sus necesidades, y mayor intermediación en la gestión activa de su demanda. Y todo ello, tiene sentido gestionarlo desde cooperativas y/o plataformas $P 2 P$ de intercambio de energía entre consumidores, que es el punto al que queríamos llegar.

A estos efectos, conviene distinguir entre los conceptos de Gestión de la Demanda Eléctrica (GDE) y Gestión Activa de la Demanda Eléctrica (GADE). La Gestión de la Demanda Eléctrica (GDE) es el conjunto de acciones cuyo objetivo común es influir sobre el uso que los consumidores hacen de la electricidad, de forma que se produzcan los cambios deseados, tanto para producir un ahorro de energía como para aumentar la eficiencia ${ }^{39}$. La Comisión Europea, en un análisis realizado para diseñar la estrategia a seguir para garantizar la seguridad de suministro energético concluye que, ante las escasas posibilidades para actuar en el suministro, esta debe concentrarse en la actuación sobre la demanda ${ }^{40}$.

La combinación de la GDE con tecnologías de generación fotovoltaica de última generación (inversores conectados a red con sistemas de almacenamiento de pequeña escala y control activo de la interfaz de red) permite llegar a un nuevo concepto llamado Gestión Activa de la Demanda Eléctrica (GADE), que no solo permite optimizar el uso de la generación fotovoltaica, sino que puede proporcionar beneficios para otros consumidores conectados a la red eléctrica (a través de estrategias cooperativas), así como para la propia red. Los consumidores residenciales pueden ser los primeros beneficiados del uso de estrategias de GADE mediante el uso de tecnologías de control que faciliten (automaticen) las tareas de gestión de la demanda sin comprometer la satisfacción de necesidades y preferencias del usuario ${ }^{41}$.

La GADE también recibe el nombre de «agregador de la demanda» y se trata de una figura que podría agrupar distintos agentes del sistema eléctrico, como consumidores, autoconsumidores, mini-productores, prosumidores, baterías, puntos de recarga de vehículos eléctricos, o cualquier combinación de todos estos, para actuar como una sola entidad y participar en el mercado eléctrico (tanto mayorista como minorista) o vender servicios al operador del sistema.

Esta gestión activa de la demanda eléctrica es esencial puesta en coordinación con la eficiencia energética, el fomento de la generación de electricidad a través de fuentes de energía renovables y el autoconsumo. Hacia todo ello, se mueven y se

\footnotetext{
39 Pérez et al. (2005).

40 Comisión Europea (2002).

41 Hinnells (2008).
} 
moverán en 2019, las políticas y regulaciones tanto a nivel europeo, como nacional. A nivel europeo, en abril de 2018, entró en vigor la Directiva 2018/844/UE del Parlamento Europeo y del Consejo, de 30 de mayo, por la que se modifican las Directivas 2010/31/UE y 2012/27/UE relativas a la eficiencia energética. Entre sus fortalezas, figuran las de promover las ayudas para la rehabilitación de los edificios, el certificado de eficiencia energética y la instalación de estaciones de recarga para vehículos eléctricos en los edificios, además de la lucha contra la pobreza energética. Se fijan los siguientes compromisos: 1) de reducción de las emisiones de gases de efecto invernadero de al menos el 40 por 100 de aquí a 2030, en comparación con 1990; 2) de aumentar a un 27 por 100 la cuota de aprovechamiento de las fuentes de energía renovable, y 3) de reducir el consumo energético mediante la mejora de la eficiencia energética en un 27 por 100.

Mientras que, en noviembre de 2018, el Parlamento Europeo aprobó la Propuesta de Directiva del Parlamento y del Consejo, relativa al fomento del uso de energía procedente de fuentes renovables, que tendrá que transponerse a las normativas nacionales antes del 30 de junio de 2021. Su objetivo es duplicar la actual tasa de renovables, aumentar la seguridad jurídica y simplificar los procedimientos administrativos, crucial todo ello para favorecer las inversiones. La Directiva sobre energías renovables establece un objetivo vinculante del 32 por 100 en el uso de energías renovables para 2030, lo que va a tener impacto en la lucha contra la contaminación y el cambio climático, e incluye una cláusula de revisión en 2023. Además, consagra el autoconsumo como un derecho.

Por su parte, a nivel nacional, el 5 de octubre de 2018, se promulgó el Real Decreto-ley 15/2018, de medidas urgentes para la transición energética y la protección de los consumidores que, entre otras cuestiones, regula el autoconsumo y elimina el denominado «impuesto al sol» (que no eran sino los cargos asociados a los costes y otros servicios del sistema eléctrico, por el uso de las redes), que recogía el Real Decreto 900/2015, de 9 de octubre, por el que se regulan las condiciones administrativas, técnicas y económicas de las modalidades de suministro de energía eléctrica con autoconsumo y de producción con autoconsumo ${ }^{42}$.

Por autoconsumo, se entiende el consumo por parte de uno o varios consumidores de energía eléctrica proveniente de instalaciones de producción próximas a las instalaciones de consumo y asociadas a las mismas. A falta de desarrollo reglamentario, son dos los tipos de autoconsumo (ex. art. 9 de la Ley 24/2013, de 26 de diciembre, del Sector Eléctrico): 1) Modalidad de suministro con autoconsumo sin excedentes: cuando los dispositivos físicos instalados impiden la inyección alguna de energía excedentaria a la red de transporte o distribución. En este caso existe un único tipo de sujeto: el sujeto consumidor. 2) Modalidad de suministro con autoconsumo con excedentes: cuando las instalaciones de generación pueden, además de suministrar energía para autoconsumo, inyectar energía excedentaria en las redes de transporte y distribución. Existen dos tipos de sujetos: el sujeto consumidor y el productor.

\footnotetext{
${ }^{42}$ Consejo Económico y Social (2017).
} 
Una de las cuestiones más interesantes en 2019, será comprobar el desarrollo reglamentario concreto que se haga del Real Decreto-Ley 15/2018, convalidado por el Congreso de los Diputados mediante resolución de 18 de octubre de 2018.

También resultará relevante, para el intercambio $P 2 P$ de energía, atender al juego que se dé: 1) al autoconsumo compartido, que el RD 900/2015 prohibía en origen y, sin embargo, es permitido por el RD-Ley 15/2018, no solo entre las instalaciones que estén conectadas en la red interior de los consumidores asociados, o unidas a estos a través de líneas directa, sino también las conectadas a la red de baja tensión derivada del mismo centro de transformación; 2) a cómo varias instalaciones de autoconsumo independientes van a poder compartir, de forma práctica, elementos de acumulación (baterías), tal y como les permitía el RD 900/2015; y 3) a la figura del «agregador de la demanda», ya referido.

La realidad es que, a medida que vaya desarrollándose la normativa pendiente, en 2019 podremos empezar a asistir al desarrollo de proyectos de intercambios de energía $P 2 P$ entre consumidores, especialmente sobre tecnología blockchain, para garantizar la trazabilidad de las transacciones.

\section{Política}

La «dinámica de plataformas» está ampliando y redefiniendo el espacio de lo político y la forma de actuar en él. Las plataformas, como lugar y como mecánica, someten también a los sujetos a un replanteamiento generalizado de las figuras intervinientes, sus relaciones y objetivos. Nos explicamos: la economía colaborativa, de base digitalizadora, horizontal, multidireccional e inmediata, ha provocado la activación política de sujetos que permanecían al margen de las cadenas de toma de decisiones, inventando y reinventando nuevos sujetos políticos, nuevos vehículos de expresión de ideas y nuevos espacios para el encuentro -y también para el desencuentro-. Las oportunidades que esta expansión y aceleración del espectro político ofrecen son difícilmente sobreestimables.

Anudado a lo anterior, la atomización que provoca el crecimiento de sujetos y espacios hará cada vez más difícil de identificar el valor inherente a cada propuesta o «plataforma», y por tanto, la decisión informada menos accesible, a la par que más sencilla la manipulación. En paralelo, la difuminación del control último de las plataformas ante la superposición de capas de colaboradores no centralizados, opaca el conocimiento de este control, pero en absoluto lo extingue. La opacidad de las plataformas no permite identificar a los propietarios o promotores, que ejercen un poder no sujeto a rendición de cuentas. Además, las nuevas formas de articulación y organización (tecnológica) permiten la extensión de tácticas, como la de guerrillas, que, si bien no son ajenas a la política, exigen una transparencia máxima para evitar que los derechos sociales y políticos del resto de ciudadanos resulten violentados.

Encontramos que las oportunidades y los riesgos o desafíos, son dos caras de una misma moneda, una tensión aún por resolver: El crecimiento y proliferación de 
sujetos políticos en plataformas tendrá que evitar, para ser valioso, que una excesiva atomización o radicalización impidan un conocimiento suficiente de dos preguntas esenciales: cuál es la propuesta política y quién es el sujeto proponente.

Encontramos así que la dinámica de plataformas se propone como colaborador/ competidor de la política tradicional y como amigo/enemigo de los modos de participación política.

Nos referiremos siempre a la «mecánica o dinámica de plataformas», para englobar el conjunto de efectos que posee, en el ámbito del ejercicio de la política o su estudio, el empleo de los razonamientos y soluciones que articula la economía de plataformas, es decir, los espacios que crea y las formas de participación que inventa.

De manera preliminar, puede plantearse lo que sigue: La dinámica de plataformas permite incorporar a la «arena» política una serie de elementos y técnicas que provocan la superación de las formas de participación existentes, articulando nuevos sujetos y formas de participación política, a la vez que aporta dimensiones -adicionales o alternativas- a la forma clásica de intervención política: el partido. Y lo hace de forma descentralizada, tecnológica, de bajo coste pero opaca y carente de herramientas para asegurar la dación de cuentas.

Vamos a referirnos a estos nuevos sujetos y vías de participación, primero. A continuación, lo haremos a las nuevas posibilidades para el mensaje y la reducción de costes, después. Son oportunidades, en todo caso. Apuntaremos finalmente el desafío de combatir la opacidad y la falta de rendición de cuentas.

La dinámica de plataformas se reproduce en la política para superar las manifestaciones conocidas de participación, que se extienden a sujetos que permanecían ajenos a la política, creando nuevos sujetos.

Las nuevas formas de participación, cuya clasificación sería inútil ${ }^{43}$, comparten ciertas características: $a$ ) son de coste reducido; $b$ ) articulan intercambios multidireccionales y recurrentes de información; $c$ ) se despliegan en entornos tecnológicos; d) aparentemente descentralizados; $e$ ) con representatividad perfecta.

Si bien es un fin inequívoco de todas ellas el de incidir en la articulación del poder político, estas plataformas comparten dos dimensiones que las definen: $a$ ) no es necesario que pretendan alcanzar ese poder político; $b$ ) este no es su único fin, pudiéndose constatar otros muchos propósitos igualmente valiosos, no ajenos a la política.

Estas dos circunstancias no son meramente secundarias porque:

- Primero, han «atraído» a sujetos y grupos sociales tradicionalmente excluidos o desinteresados de la política.

- Segundo, han configurado nuevos sujetos políticos, que son tenidos en consideración para la fijación de la agenda política y, en última instancia, para la toma de decisiones políticas.

${ }^{43}$ En los últimos años, observamos el nacimiento y crecimiento de numerosas plataformas políticas que evidencian las antedichas características. El Movimiento 15-M, Podemos, Ciudadanos, En Marche, el Movimiento 5 Estrellas, el movimiento STOP Desahucios, Occupy Wall Street, \#Metoo o los Comités de Defensa de la República, o CDR. Son una pequeña muestra de organizaciones surgidas. 
Debe concluirse que la reproducción de la «dinámica de plataformas» en el ámbito de lo político ha ampliado el mapa político, articulando políticamente sujetos inactivos y llegando a crear sujetos en el ámbito político.

Nos encontramos ante una gran oportunidad: en el futuro próximo, este nuevo «mapa» tendrá cada vez mayor relevancia no solo por resultar imprescindible para entender cómo se forma y ejerce el poder, sino porque este proceso expansivo no está agotado; ni las fuentes de cambio están restringidas. Es decir: la capacidad efectiva de ampliar el espectro político y de activar y crear nuevos sujetos será el elemento que distinga a los modelos políticos de éxito. Y no cabe anticipar desde dónde brotarán estas nuevas propuestas.

En segundo lugar, la «dinámica de plataformas» ha impactado en todos los niveles del mensaje político: nos hemos referido a los sujetos, pero todas las dimensiones del mensaje (desde el contenido al canal), están experimentando un proceso de renovación que llega a «revalorizar y cambiar en gran medida la cultura política» (Miró, 2015).

El proceso de transformación del mensaje político ha sido un continuo desde el comienzo del siglo XXI, cuando «el ejercicio de la política se somete a procesos horizontales y transversales que propician una democracia participativa desconocida hasta ahora» (Morcillo, 2015), sin que pueda atribuirse este fenómeno, imparable, a la dinámica de plataformas.

La dinámica de plataformas, en cambio, ha propiciado dos revoluciones de no menor calado:

- Primero, ha generalizado el fenómeno de la escucha masiva. Se trata de la creación del mensaje por medio de la apertura a la recolección del criterio, de forma masiva, por cada uno de quienes habían sido considerado como destinatarios y no como emisores.

- Segundo, la emancipación del mensaje con respecto de la organización que lo articula, y en concreto, cuando es un partido político el que lo origina. Esto es: los partidos políticos (aunque no solo, también otras instituciones) tenían una relación bidireccional con las ideas y el mensaje que presentaban al mercado, estableciéndose una doble identificación. El partido determinaba su mensaje, y su mensaje define al partido. La articulación de mensajes total o parcialmente incompatibles con la percepción ideológica de un determinado partido provoca una pérdida de confianza del electorado, y su consecuencia necesaria es la esclerotización del catálogo de propuestas de valor del partido. En síntesis: por temor a defraudar, o a confundir, al potencial electorado, los partidos políticos renuncian a lanzar mensajes innovadores, renunciando a soluciones innovadoras.

La dinámica de plataformas supera esta deficiencia, en tanto que permite a estas instituciones lanzar propuestas de valor y mensajes a través de plataformas creadas ad hoc para un determinado problema o contexto. Estas plataformas gozan de todos 
los elementos de imagen y contenido que les permiten definirse como independientes del partido. Incluso aunque el votante sea consciente de su pertenencia al partido, su vinculación con este es más débil, y por tanto, el coste de oportunidad que le supone plantearlo es muy inferior.

Esto permite, por un lado, al partido lanzar ideas y propuestas de valor no totalmente coincidentes, e incluso contradictorias, con su ideología formal, propiciando la evolución ideológica del conjunto de algunas de esas ideas, teóricamente, las mejores de ellas. En segundo lugar, permite la construcción de propuestas de valor con el apoyo de poblaciones no íntegramente coincidentes con su corpus de simpatizantes o afiliados.

Para instituciones y sujetos ajenos a la iniciativa, el coste de apoyar a la plataforma es muy inferior, precisamente por razón de no proceder, directamente, de un partido. Se genera de esta forma un espacio adicional de convivencia o diálogo, de propiedad compartida, con menor coste de pertenencia y aportación. Pensemos por un momento en el coste que entrañó para el PSOE el apoyo - velado- que articuló a la entrada española en la OTAN y en lo sencillo que resultaría hoy evitar este coste mediante la articulación de sujetos y mensajes en forma de plataforma.

Sin duda, la dinámica de plataformas provoca un incremento tanto del volumen innovador en el proceso político, como de la probabilidad de acuerdos y puntos de encuentro entre diferentes actores políticos, sean partidos políticos como otras instituciones, tradicionales o específicamente nacidas en el seno de la dinámica de plataformas.

La permeabilidad de ideas y poblaciones favorece la generación de puntos de encuentro, mejorando la calidad democrática y de las instituciones que las componen.

La economía de plataformas, allá donde opera, genera una considerable reducción de $\operatorname{costes}^{44}$, fenómeno que se reproduce en el caso de la política. En esencia, este ahorro nace de la escasa necesidad de bienes de equipo de las plataformas y de la reducción de los costes fijos y operativos, sustituidos por contribuciones desinteresadas y descentralizadas de los usuarios ${ }^{45}$.

Un ejercicio de la política con menores costes habrá de conducir, aún más, a una completa reordenación de por quién y cómo se hace la política. En primer lugar, es de esperar que continúe acrecentándose el número de propuestas políticas, y por razón de su mayor número, mejor especialización y especificidad, es decir, ordenación a un fin concreto, medible y, por tanto, alcanzable. Segundo, y por lo anterior, una mayor atomización del espectro político, donde los ejes tradicionales para la categorización política ${ }^{46}$ pierden su valor analítico y, en consecuencia, la identificación de principios, premisa para toda decisión informada, se dificulta.

Debemos señalar que toda plataforma política es tributaria de una voluntad de influir, cuando no de controlar. Todo sujeto posee un promotor que, en el caso de la

\footnotetext{
${ }^{44}$ Rodrik (2018).

45 Loi (2016).

46 Estes (1971).
} 
dinámica de plataformas se hace invisible por razón de una aparente (y no tan aparente) descentralización. Que la intención existe es tan indudable como que también existe el control, por personas, en las plataformas. Los riesgos -desafíos- de una invasión del ámbito político por sujetos consagrados a la destrucción del espacio, o aún más, de la convivencia, son evidentes. Un compendio, siquiera superficial, de los peligros de legitimar por esta vía actuaciones incardinables en lo vandálico incluso delictivo se observa en la dinámica de los CDR en el modelo de convivencia español ${ }^{47}$.

Si bien el análisis de estos riesgos excede el alcance de este estudio, en ningún caso deben ser ignorados o preteridos, pues de su control -y examen- depende que la dinámica de plataformas no se erija en una oportunidad de mejora de la convivencia, frustrada.

\section{Administraciones Públicas}

Las Administraciones Públicas (AA. PP.) pueden y deben ser una figura clave dentro del ecosistema digital, estableciendo sinergias con la economía colaborativa y los nuevos modelos de negocio en las plataformas digitales. Antes de centrarse en el «cómo» convertirse en esta pieza esencial, el sector público debe poner el foco en el «qué» entiende por ecosistema digital, y para ello debe analizar sus necesidades actuales y futuras, debe reflexionar sobre cómo va a impactar la tecnología en este ámbito y debe construir relaciones sólidas y simbióticas con agentes del cambio como startups, emprendedores, hubs tecnológicos u otras corporaciones e instituciones.

Por otro lado, es imprescindible hacer hincapié en algo tan necesario como es la formación. Sin ella, el proceso de transformación en la que se encuentran las AA. PP. será un fiasco. Hoy por hoy -y probablemente no cambiará- existe una necesidad imperiosa de formarse constantemente e ir adquiriendo nuevas habilidades y capacidades digitales, algo que no se potencia en el sector público. Además, esta brecha se irá agrandando si se tiene en cuenta el último informe de World Economic Forum sobre el futuro del trabajo. Según el estudio, dos de las tres principales habilidades para el 2020 -tener pensamiento crítico y creatividad- en 2015 estaban en posiciones mucho menos relevantes.

En esta etapa del cambio, la responsabilidad de las AA. PP. es doble. Por un lado, tienen que abordar internamente el proceso de transformación digital, como hemos comentado. Y por el otro, tienen un papel importantísimo para combatir aspectos tan negativos, fruto de la innovación tecnológica, como es la brecha digital entre personas, ciudades y regiones, donde en muchos casos la era digital lejos de ser inclusiva, social y justa, está generando diferencias significativas en las sociedades entre los que están capacitados y los que no. Además, como bien apunta Manuel Muñiz en su tribuna «Tecnología y orden global» en el diario El País, la concentración de talento

\footnotetext{
${ }^{47}$ Puede consultarse la guía de los errores que se pueden cometer en Costa (2018).
} 
sofisticado en hubs, clusters o ecosistemas digitales de determinadas zonas geográficas del mundo están provocando, inequívocamente, una grave fractura social.

Las AA. PP., como muchos otros sectores, tienen la necesidad de 1) digitalizarse para mejorar procesos, ser más ágiles y operar de manera más eficientemente y 2) de transformarse para seguir aportando valor a la sociedad y a la economía. En ambos casos las administraciones precisan de una estrategia que defina por un lado qué tecnologías e innovaciones deben adoptar para digitalizarse y, por otro, algo que requiere mayor trabajo y reflexión: una estrategia para transformarse y adaptarse a los nuevos tiempos.

Es muy común -y no solo en las Administraciones Públicas- cuando se define una estrategia de transformación digital caer en el error de querer incorporar las nuevas tecnologías sin haber pasado antes por un proceso de análisis y estudio de las necesidades y de los requerimientos que se precisan de ellas. La transformación conlleva muchos aspectos que a veces poco tienen que ver con la tecnología. Más bien requiere de pensamiento crítico y profundo dado que afecta a la cultura de la propia empresa, a las habilidades de las personas que la conforman, a las metodologías utilizadas y al modelo con el que se ha estado operando durante años. Hay que tener en cuenta, pues, que el proceso de transformación digital es un proceso de cambio cultural empresarial.

Dada la complejidad que conlleva la transformación digital, es necesario que cada administración defina su hoja de ruta y un marco de trabajo para desarrollar una estrategia óptima. Por ello, entender en qué punto está una administración en concreto resulta clave para empezar a trabajar. De no ser así, ¿cómo se puede saber qué aspectos hay que cambiar? ¿Qué tecnología es la que se tiene que adoptar para seguir aportando valor? ¿Cómo atraer la innovación y potenciar el talento que hay en la empresa pública para responder a las expectativas de los ciudadanos?

Si se evalúan y se analizan las necesidades se puede llegar a la conclusión de que quizá lo que se tiene que hacer es redefinir el cómo se está utilizando una tecnología, y empezar a hacerlo de manera correcta. O quizá lo que se necesita es establecer sinergias con modelos colaborativos y/o de plataforma para mejorar en eficiencia y costes. Pero sin duda, sea la opción que sea, para poder sacar buenas conclusiones se tiene que realizar una auditoría y un análisis previamente.

Las Administraciones Públicas y otros sectores -como el privado- deben seguir colaborando para el beneficio de todos, pero también entre la propia Administración debe existir mayor colaboración y adquirir nuevas formas de cooperación entre miembros, departamentos y áreas de trabajo, incorporando así metodologías ágiles, la cocreación o la innovación abierta. Estas formas de colaboración pueden ser de manera presencial o en remoto a través de plataformas digitales.

Introducir metodologías Lean o Agile, empezando con grupos pequeños testando los resultados de un proyecto colaborativo donde se ha introducido una innovación o tecnología (por ejemplo una nueva plataforma de gestión) y evaluando los resultados para obtener aprendizajes es algo muy valioso para un proceso de innovación y/o de transformación. Crear redes de intercambio de conocimiento a través de plataformas 
digitales entre homónimos, departamentos o entidades públicas, son formas de generar inteligencia colectiva y de estimular una cultura colaborativa entre peer to peer dentro de la Administración.

Afortunadamente en España hay cada vez más colaboración público-privada. Una de las líneas principales de colaboración que debe seguir trabajando las AA. PP. es la de aprovechar los datos que generan empresas o startups de la economía colaborativa o de plataforma como son Cabify o Airbnb. Siendo esta última una de las que más está colaborando con diferentes administraciones locales en España para la regulación y registro de pisos turísticos. Por otro lado, hubs tecnológicos como Barcelona Tech City se están aliando a través de plataformas digitales con Ayuntamientos e iniciativas públicas para atraer y retener talento en una zona geográfica determinada.

Y ya por último, otro punto interesante es cómo las AA. PP. han entendido el poder de las plataformas digitales y han desarrollado proyectos como Sentilo (plataforma para la gestión de datos públicos) o Decide (plataforma para la participación e inteligencia ciudadana).

Además, al ser de código libre y abiertas, se reducen los costes a la hora de implementar el proyecto, pero también se pueden mejorar y actualizar de manera ágil y sin coste con la ayuda de la comunidad de desarrolladores. En definitiva, inteligencia colectiva y resiliencia tecnológica pública como nunca se había visto antes y al servicio de toda la sociedad.

\section{Conclusiones}

En la introducción y las diversas secciones de este artículo podemos observar como la economía colaborativa y los elementos que la conforman tienen una enorme aplicación práctica en nuestra sociedad y economía. Si pensamos en su proyección futura, su creciente integración en nuevos ámbitos públicos y privados resulta evidente, a lo que contribuirá el constante impulso de la conectividad y de la reducción de la brecha digital en determinados ámbitos geográficos y grupos sociales.

Para que se logre un desarrollo, maximización de bienestar social y mejora del modelo colaborativo, debemos adelantarnos y analizar sus potenciales problemas y externalidades positivas, a la prospectiva de tendencias. Se requerirá una combinación de competencia dentro del mercado y regulación, facilitando un diálogo estructurado entre los protagonistas para la determinación de las mejores reglas de juego en aspectos horizontales y sectoriales: competencia, normativa laboral, privacidad e impuestos ${ }^{48}$. Para contribuir en lo anterior, la presente conclusión, a modo de cierre de este artículo «experimental», que quiere sumar claves o líneas de trabajo para promover el mejor futuro para la economía colaborativa.

${ }^{48}$ Tirole $(2017,2018)$. 
La economía colaborativa tiene como una de sus cuestiones características el debate público y regulatorio que viene suscitando. Aunque resulta compleja una aproximación de ordenación general al fenómeno, sí que existen elementos que deben tenerse en cuenta por los poderes públicos a la hora de contribuir al encaje de las actividades que engloba. Entre estos debemos destacar: su constante variabilidad y evolución, algo que exige replantear como las Administraciones deben relacionarse con las plataformas y las comunidades de usuarios que abarcar, las que, recíprocamente, precisan también de una adecuada interacción con sus reguladores; la transparencia y trazabilidad que caracteriza al modelo, algo que las Administraciones no solo pueden ver cómo una vía de incrementar su «control público» sino como una vía para dinamizar la gestión pública para los ciudadanos y la actividad económica; y, finalmente, prestar mayor atención al papel de las ciudades, como estas deben jugar un papel protagonista extrayendo valor del modelo de plataforma y colaborando con aquellas en pilotos (sandbox) para probar nuevos modelos colaborativos o en nuevas metodologías para perfeccionar aspectos complejos. Un ejemplo reciente es el manifiesto de 48 ciudades internacionales para reivindicar mayor soberanía regulatoria en materia de tecnología y servicios digitales, lo que puede abrir líneas de regulación colaborativa y de testeo.

Diversos organismos públicos y grandes empresas están impulsando proyectos usando elementos de la economía colaborativa, tanto para generar nuevos productos o servicios como, también, para mejorar sus dinámicas internas. Este es solo el principio, la plataformización y la interacción entre iguales (peers) facilita el crecimiento y conocimiento de las organizaciones. Algo que ha sido desarrollado por uno de los contribuidores a este artículo, Javier Creus, quien en 2016 diseñó el sistema Pentagrowth para ayudar a grandes organizaciones a incorporar dinámicas colaborativas en su crecimiento.

En todos los sectores analizados, el crecimiento exponencial de las plataformas digitales permite el aprovechamiento de externalidades positivas, pero también ha acelerado externalidades negativas, reacciones del sector público restrictivas del mercado y la identificación de aspectos de mejora del fenómeno. El diagnóstico está hecho mayormente, lo que representa una oportunidad para un entorno digital que quiere construir soluciones en ambientes de competencia y en colaboración con los decisores públicos o privados de los que depende y a los que sirve.

A día de hoy ya se han identificado algunos de los aspectos que podrían ser objeto de desarrollo. Entre los que destaca el impulso de sistemas para la portabilidad de la reputación de los usuarios, medidas para salvaguardar la privacidad, maneras de desincentivar la discriminación por sexo, raza, religión y, también, edad. Asimismo, encontramos posibles mejoras de la normativa laboral para facilitar la protección y contribución de las nuevas formas de trabajo, incorporando cuestiones vinculadas a las condiciones laborales de las personas que trabajan a través de plataformas o el impulso de sistemas para facilitar la contribución impositiva de las plataformas, garantizando una adecuada declaración fiscal de los ingresos que se generen. 
Los diferentes apartados del artículo muestran que la economía colaborativa y modelos similares representan una oportunidad para «re-descentralizar» internet y el sistema económico no digital, mejorando su funcionamiento. El poder de la colaboración en línea, tanto crowd o peer, potenciado con tecnologías blockchain, es un posible camino para conseguirlo.

Es discutible si la tecnología tiene o no ideología. En el caso de la economía colaborativa, la batalla de las ideas se está manifestando a diversos niveles. La tensión económica, social e ideológica que supone, a nivel mundial, debería ayudar a encontrar múltiples soluciones y comparar entre ellas. Las administraciones en España están eligiendo una de las vías más restrictivas entre todos los países del mundo. En los próximos años vamos a ser partícipes, voluntarios o involuntarios, de un costoso experimento natural. Será de importancia seguir observando la evolución de estos modelos en los diversos países y analizar si la regulación ineficiente y los obstáculos a la competencia ralentizan la innovación tecnológica en la economía colaborativa. O si, por el contrario, la tecnología mantiene su ritmo de evolución y permite ayudar a determinar el marco legal, la economía y, en último término, revelar las elecciones de los ciudadanos y sus preferencias sociales.

\section{Referencias bibliográficas}

ACCO (2012). Reflexiones procompetitivas sobre el modelo regulador del taxi y del arrendamiento de vehículos con conductor (Ref. OB 11/2011). Recuperado de http://acco.gencat. cat/web/.content/80_acco/documents/arxius/actuacions/reflexiones_taxi_vtc_esp.pdf

ACCO (2014). Transacciones entre iguales (p2p) y competencia (Ref. ES 7/2014). Recuperado de http://acco.gencat.cat/web/.content/80_acco/documents/arxius/actuacions/ ES_7_2014_TRANSACCIONES_ENTRE_IGUALES_Y_COMPETENCIA_CAST.pdf ACCO (2016). Transacciones entre iguales ( $p 2 p)$. Un paso adelante. (Ref. ES 10/2015). Recuperado de http://acco.gencat.cat/web/.content/80_acco/documents/arxius/actuacions/ P2P-Un-pas-endavant_DEF_es-vX.pdf

ACCO (2018a). Estudio sobre el sector del transporte de viajeros en vehículos de hasta nueve plazas: el taxi y los vehículos de alquiler con conductor (Ref. ES 15/2108), junio. Recuperado de http://acco.gencat.cat/web/.content/80_acco/documents/arxius/actuacions/20180628_estudi_taxi_veh_lloguer_esp.pdf

ACCO (2018b). Valoración, desde una óptica de competencia, del Real Decreto-Ley 13/2018, de 28 de septiembre, por el cual se modifica la LOTT (Ref.: OB 40/2018), octubre. Recuperado de http://acco.gencat.cat/web/.content/80_acco/documents/arxius/actuacions/ ES-OB-40-2018-Valoracio-RDL-13-2018_23102018cast.pdf

AFI (2017). Impacto socioeconómico de la modernización de los servicios VTC. Recuperado de http://www.afi.es/afi/libre/pdfs/grupo/documentos/completo\%20170510_informe.pdf

American Public Transportation Association (2016). Shared Mobility and the transformation of public transit. Recuperado de https://www.apta.com/resources/reportsandpublications/ Documents/APTA-Shared-Mobility.pdf

Byung-Chul H., (2014). La sociedad del cansancio. Barcelona: Pensamiento Herder.

Cleantech Group, (2014). Homesharing Greener Than a Usual Hotel. Recuperado de https:// cleantechnica.com/2014/08/11/ homesharing-airbnb-greener-usual-hotel/ 
Comisión Europea, (2002). Towards a EU strategy for the security of energy supply, COM (2002) 321.

Comisión Europea (2016). Study on passenger transport by taxi, hire car with driver and ridesharing in the EU. Recuperado de https://ec.europa.eu/transport/sites/transport/files/2016-09-26-pax-transport-taxi-hirecar-w-driver-ridesharing-final-report.pdf

Comisión Nacional de los Mercados y la Competencia (CNMC) (2016a). Estudio sobre los nuevos modelos de prestación de servicios y la economía colaborativa. Resultados preliminares (E/CNMC/004/15). Recuperado de https://docs.google.com/document/d/1n65MjUaTmRLuZCqTIlqyWvobVqreR-iAzsz1mhxy2y0/edit

Comisión Nacional de los Mercados y la Competencia (CNMC) (2016b). Informe económico sobre las restricciones en la competencia incluidas en el Real Decreto 1057/2015 y en la Orden FOM/2799/2015, en materia de vehículos de alquiler con conductor. Recuperado de https://www.cnmc.es/file/107176/download

Comisión Nacional de los Mercados y la Competencia (CNMC) (2017a). Estimación del daño ocasionado por el régimen de monopolio en los servicios de taxi en España. Recuperado de https://www.cnmc.es/sites/default/files/editor_contenidos/Promocion/CNMC_ 001_2017.pdf.

Comisión Nacional de los Mercados y la Competencia (CNMC) (2017b). ¡No entiendo nada! ¿Cómo se fija el precio de la luz? CNMC Blog. 20 diciembre 2017. Recuperado de https://blog.cnmc.es/2017/12/20/no-entiendo-nada-como-se-fija-el-precio-de-la-luz/

Comisión Nacional de los Mercados y la Competencia (CNMC) (2018). Estudio sobre el impacto en la competencia de las nuevas tecnologías en el sector financiero (FINTECH). E/CNMC/001/18, Madrid.

Consejo Económico y Social (2017). El sector eléctrico en España. Informe 04/2017.

Costa, D. (2018). Los CDR nueva herramienta política. Recuperado de http://kaosenlared. net/los-cdr-nueva-herramienta-politica/

Deutsche Bundesbank (2016). Technology-enabled financial innovations: a source of opportunities and risks. Financial Stability Review, 67-77.

Estes, N. (1971). The Concept of Shared Power. The Bulletin of the National Association of Secondary School Principals, 55(355),69-75.https://doi.org/10.1177/019263657105535508

García F., Trebolle D., Gaudó M., Galán J. M., Linares P., \& Conchado A. (2013). Gestión de la demanda eléctrica. Anales de Mecánica y Electricidad, 90(4), 26-32.

Groizard, J. L, \& Nilsson, W. (2017). Mito y realidad del alquiler vacacional en las Islas Baleares. Palma de Mallorca: Universitat de les Illes Balears. Recuperado en noviembre $2018 \mathrm{de}$ http://dea.uib.cat/digitalAssets/430/430024_w84.pdf

Guirado, R. et al. (2006). Energía en España y desafío europeo. Seguridad de suministro. Concentración. Regulación y Competencia. Grandad: Editorial Comares.

Hinnells, M. (2008). Technologies to achieve demand reduction and microgeneration in buildings. Energy Policy, 36(12).

Loi, M. (2016). The Uberization of Politics: the success of the Five Stars Movement explained by 10 analogies with the sharing economy. Recuperado de https://www.academia.edu/.

Maudes, A., \& Silos, M. (2016). Una regulación económica más eficiente en el mundo digital. Las autoridades independientes de productividad. Revista ICE (891), 61-79. Recuperado de http://www.revistasice.com/index.php/ICE/article/view/1865/1865

Maudes, A., Sobrino, M., \& Hinojo, P. (2016). Fundamentos económicos de la economía colaborativa. Anuario de la competencia (pp. 167-186). España: Marcial Pons. 
Mendoza, J. \& Hernández R. (2017). Una propuesta metodológica para la medición de la sostenibilidad del turismo a escala local. Cuadernos Económicos de ICE (93), 69-90.

Miró, M. (2015). La comunicación política en la era digital: El papel de Facebook en la ciberdemocracia y como espacio de diálogo entre políticos y ciudadanía en España. Repositorio Universidad Jaume I.

Morcillo, G. (2015). Discursos políticos del siglo XXI: De la elocutio a la inventio. Recuperado de https://compolitica.com/la-revista/tendencias

Nicoletti, B. (2017). The Future of Fintech: Integrating Finance and Technology in Financial Services. London: Palgrave Macmillan.

OCDE (2007). Taxi services: Competition and Regulation DAF/COMP(2007)42. Policy Roundtable. Recuperado de http://www.oecd.org/regreform/sectors/41472612.pdf

OCDE (2018). Taxi, ride-sourcing and ride-sharing services - Background Note by the Secretariat. Working Party No. 2 on Competition and Regulation, DAF/COMP/WP2. Recuperado de https://one.oecd.org/document/DAF/COMP/WP2(2018)1/en/pdf

Ojea, L. (2018). Un nuevo agente entra en el mercado eléctrico español: el 'agregador' de la demanda. El periódico de la energía.

Pérez J. I., Sánchez, L.J., \& Pardo, M. (2005). La gestión de la demanda de electricidad. Madrid: Fundación Alternativas.

Rodríguez, F. (2018). Del hospitium al turismo 4.0. Madrid: Libros.com.

Rodríguez S., \& Muñoz A., (2018). Aspectos legales de la economía colaborativa y bajo demanda en plataformas digitales. Madrid: Bosch.

Rodrik, D. (2018). Populism and the Economics of Globalization. Journal of International Business Policy, 1, 12-33.

Seeman, M. (2017). Was ist Plattformpolitik? Grundzüge einer neuen Form der politischen Macht. Zeitschrift für sozialistische Politik und Wirtschaft (SPW).

Segond, R. (2016). Vers la plateformisation de la politique. Recuperado de https://medium. com/@Romain2nd

Sevilla, J. \& Riesgo, A. (2018). Qué está pasando con tu sanidad. Barcelona: Bresca.

Tirole, J. (2017). La economía del bien común. España: Taurus.

Tirole, J. (2018). Regulating the disrupters. LiveMint Project Syndicate.

Vives, X. (2006). El reto de la competencia en el sector eléctrico. En Del monopolio al mercado. La Comisión Nacional de Energía: diez años en perspectiva. IESE Business School Occasional Papers.

World Economic Forum (2017). Beyond Fintech: A Pragmatic Assessment Of Disruptive Potential In Financial Services. Prepared in collaboration with Deloitte.

Zetzsche, D. A., Buckley, R. P., Arner, D. W., \& Barberis, J. N. (2017). From FinTech to TechFin: The Regulatory Challenges of Data-Driven Finance. EBI Working Paper Series, n. 6. 